\title{
Stress intensity solutions for cracked orthotropic plates
}

\author{
A. Sahli, S. Kebdani, D. Boutchicha, and O. Rahmani \\ University of Sciences \& Technology (USTO) \\ Faculty of Mechanical Engineering \\ B.P 1505 El-Menouar, 31000 Oran - Algeria \\ E-Mail : sahli@univ-usto.dz
}

\section{Abstract}

In this paper, fracture mechanics in orthotropic plates, stress and displacement distributions around the crack tip in an anisotropic material are considered.

Classical displacement based finite elements, elements with penalized equilibrium and elements with drilling degrees of freedom are employed.

The path independent integrals $\mathrm{J}$ and $\mathrm{I}^{*}$ are applied to orthotropic fracture mechanics problems to determine the stress intensity factor at the crack tip. Again, convergence studies are done, and the path independence of $\mathrm{J}$ and $\mathrm{I}^{*}$ are investigated for orthotropic problems. Numerical results for typical fracture specimens are presented and discussed. The effect of the degree of anisotropy and fiber orientation on the stress intensity factor is also demonstrated.

\section{References}

[1] S. Geyer, A.A. Groenwold, Two hybrid stress membrane finite element families with drilling rotations, Int. J. Numer. Meth. Eng. 53, 583-601, (2002).

[2] A.A. Groenwold, Q.Z. Xiao, N.J. Theron, Representing traction free boundaries using drilling degrees of freedom, in: B.H.V. Topping, Z. Bittnar (Eds.), The Sixth International Conference on Computational Structures Technology, Prague, Czech Republic, , Paper no. 22, September 2002.

[3] A.A. Groenwold, Q.Z. Xiao, N.J. Theron, Accurate solution of traction free boundaries using hybrid stress membrane elements with drilling degrees of freedom, Comput. Struct. 82 20712081, (2004).

[4] R.K.L. Su and H.Y. Sun. Numerical solutions of two-dimensional anisotropic crack problems. International Journal of Solids and Structures, 40: 4615-4635, 2003.

[5] Q.Z. Xiao, B.L. Karihaloo, and F.W. Williams. Application of penalty-equilibrium hybrid stress element method to crack problems. Engineering Fracture Mechanics, 63:1.22, 1999. 